\title{
Estimation of alcohol content of wine, beer and spirits to evaluate exposure risk in pregnancy: Pilot study using a questionnaire and pouring task in England
}

\author{
Raja Mukherjee ${ }^{1}$, Elizabeth Wray ${ }^{1}$, Leopold Curfs $^{2}$, and Sheila Hollins ${ }^{3}$ \\ ${ }^{1}$ FASD Behavioral Clinic, Surrey and Borders Partnership NHS Foundation Trust, Oxted, Surrey, United Kingdom \\ ${ }^{2}$ Maastricht University Medical Center, Klinische Genetica, Maastricht, Netherlands \\ ${ }^{3}$ St George's University of London, London, United Kingdom
}

\begin{abstract}
Aims: Research has shown varying results regarding safe consumption levels of alcohol during pregnancy. We argued in 2005 that an individual's inability to accurately predict her alcohol consumption may be one factor influencing risk. In order to reevaluate within the England, this study sought to assess the current knowledge of the public and of healthcare practitioners.

Design: Both alcohol-knowledge questionnaires and pouring tasks were conducted using standardised ethical-committeeapproved methods.

Settings: Different sites across England, including Surrey, London, Oxford and Wigan, where FASD support groups are based.

Participants: Health professionals and the general public, self-selecting in response to advertisement.

Measurements: Frequency data and categorical data was collected and analysed using SPSS version 18.

Findings: In total, 1,265 questionnaires were completed (688 public and 577 professionals). One hundred-forty people completed the pouring task. People's ability to calculate accurately from strength and volume was within $20 \%$ of the accurate figure for units, although with a wide range.

Conclusions: These findings support the hypothesis that when pouring their own drinks, individuals are poor at estimating each drink's alcohol content. This has implications for public health strategies. Glass size and the level of alcohol concentration have different implications in different countries. For those drinking during pregnancy, however, the message that "no exposure is no risk" remains true.
\end{abstract}

The debate surrounding a safe level of alcohol consumption in pregnancy continues to draw attention. Since our 2005 U.K. study regarding safe drinking limits in pregnancy (Mukherjee, Hollins, Abou-Saleh, \& Turk, 2005), other researchers internationally have addressed the issue, but have yet to clarify individual risk. Some studies have suggested that even low levels of exposure carry risks of, for example, mental health problems (Alati et al., 2008; Disney, Iacono, McGue, Tully, \& Legrand, 2008; Henderson, Gray, \& Brocklehurst, 2007; Patra et al., 2011; Sayal, 2009; Sayal, Heron, Golding, Altai et al., 2007; Sayal, Heron, Golding, \& Emond, 2007), while others have shown no evidence of developmental problems in comparison to non-exposed groups (Gray, Mukherjee, \& Rutter, 2007; Kelly et al., 2007; Kelly et al., 2010; O'Leary et al., 2010; Onofrio et al., 2007). We argued that in the U.K., individual women's knowledge of alcohol units, as demonstrated through their consumption levels and higher exposure risk to alcohol, was poor. Further, we argued that if they were pregnant, this increased their risk of having a child affected by prenatal alcohol exposure (Mukherjee et al., 2005).

As part of a wider study of professional and public knowledge about drinking in pregnancy and, more broadly, about Fetal Alcohol Spectrum Disorders (FASD), we

Correspondence: Raja Mukherjee, Specialist FASD Behavioral Clinic, Surrey and Borders Partnership NHS Foundation Trust, 116-118 Station Rd., East Oxted, Surrey, RH8 0QA, United Kingdom. Telephone: 01883 38378, Fax: 01883 375504. E-mail:raja.mukherjee@sabp.nhs.uk

Declaration of Interest: The FASD clinic run by Raja Mukherjee has received honoraria with respect to RM's lectures at conferences and educational meetings related to FASD from various charities, including TACT, PFC, NOFAS UK, Jannsen, and an industrial sponsor (Flynn Pharma). He is medical advisor to FAS Aware, UK FASD Trust UK and NOFAS UK.

Financial support: Funding for the project was received from Surrey and Borders Partnership NHS Foundation Trust $\mathrm{R}+\mathrm{D}$ research allocation.

Keywords: Alcohol, FAS, Pouring, Knowledge, Units, Risk 
decided to test our assumption that people were poor at accurately predicting units and poor at estimating the volume they had consumed.

The UK is made up of four nations, each responsible for its own health policy. This research was mainly conducted in England. As a wide range of beverages containing alcohol is available in the UK, alcohol is understood in terms of units. A unit of alcohol is defined as containing $8 \mathrm{~g}$ (10mls) of absolute alcohol (The Cabinet Office, 2004). The Cabinet Office recommends that for health reasons, people should not exceed a daily maximum intake of 3-4 units of alcohol for men, and 2-3 for women. Binge drinking is defined as consumption of double the daily maximum units: six units for a woman and eight for a man (Department of Health, 1995).

In 2008 an Office of National Statistics (ONS) survey suggested $83 \%$ of the population had some awareness of units. What was unclear was how accurately they were able to predict what quantity of a given beverage a unit actually contained (Lader \& Goddard, 2006).

Two reports highlight changing U.K. alcohol consumption trends. The first showed $21 \%$ of men and $14 \%$ of women were drinking more than double their recommended daily levels of alcohol per week (Office of National Statistics, 2008), and that people in higher socio-economic groups drank more (Office of National Statistics, 2008). A subsequent survey reported that people were now drinking more at home (Office of National Statistics, 2009). For women this figure was $57 \%$, with $54 \%$ claiming to drink at least weekly (Office of National Statistics, 2009). While most women in the study $(n=1,153)$ had heard about units, it was unclear how this knowledge affected their behavior (Office of National Statistics, 2009).

A series of studies published in Scotland from 2004-2007 attempted to look at this. The first asked each participant in the study group to pour a unit of wine, then spirit. The amount poured was more than double the correct volume in $43 \%$ of cases for wine, and $55 \%$ of cases for spirit (Gill \& Donaghy, 2004). Female undergraduate students asked to complete a similar task were found to pour double the original self-reported estimates (Gill, Donaghy, Guise, \& Warner, 2007). Despite the addition of a teaching intervention to the pouring task, a group of 297 mixed participants continued to pour double the accurate level, at 2.05 units (Gill \& O'May, 2007).

Outside the U.K., similar patterns have been reported. A Dutch study comparing individuals' ability to estimate standard drink measures (1.5 UK units) for wine and spirits found the group overestimated by $14 \%$ and $26 \%$ respectively. Women were $7.5 \%$ more likely to be inaccurate than men (Lemmens, 2006).

At least two reports have shown that glass size can have an effect on pouring. The first assessed 80 drinks poured in bars, showing that the biggest impact on inaccuracy was the size of the glass rather than its shape (Kerr, Patterson, Koenen, \& Greenfield, 2009). A second study, a comparison between shots poured into a small tumbler versus a long slender glass found the shape also had an effect, with 20\% more poured into the tumbler (Wasinski \& Illersum, 2005). As all these factors were considered to be an influence on exposure risk, we decided to test our hypothesis that people in England were poor at estimating units when given basic information found on many bottles sold in England, and when pouring different drinks, and that this varied by glass size and shape.

\section{METHODS}

This study was part of a wider project assessing knowledge about FASD among professionals and the general public in England using questionnaires, focus groups and a series of pouring tasks. Only aspects relating to knowledge of units and the pouring tasks are presented here.

\section{Ethical Considerations}

Permission to use unsolicited questionnaires or direct mailing was not granted by the research ethics committee, due to the sensitivity of the questions being asked about FASD. Contact with teenagers and pregnant women was also not allowed, other than in response to indirect advertising. Questionnaires had to be anonymous, preventing some direct comparison between data collected on the questionnaire and the pouring task. Separate public and professional questionnaires were mandated, due to some questions being considered too medical for the general population. Further to address consent issues, an explanation on the title page of the questionnaire, stipulating that people did not have to complete it if they chose not to, was stipulated. Finally, it was insisted that all people who were interested should be allowed to attend education sessions without being required to participate in the actual research. This accounted for some of the discrepancies in questions completed.

\section{Sample}

The project was advertised by three national FASD support groups; through direct mail to health departments; through professional networks; and though poster placement in local community centres, churches and private companies with links to the researcher's organisation. The ethicalcommittee-approved advertisement highlighted the research project, but also emphasized that the educational questionand-answer session regarding FASD was open to all. Individuals who self-selected to participate were directed via the advert to contact the research team. People working in private or public health services and in direct contact with patients were considered health professionals. All others were allocated to the general public group.

\section{Questionnaire Design}

Based upon questions raised in previous research and a smaller pilot conducted by our group (Mukherjee, Hollins, \& Turk, 2006), a series of seven questions about alcohol strength and volume were presented (Table 1). Basic information found on many current U.K. bottles containing 
alcohol—namely, percentage of alcohol and volume-was provided to assess individuals' accuracy in calculating the number of units found in each drink. These questions were not exhaustive. We began with a set of 17 questions; balancing the demands of keeping the questionnaire to an appropriate length, accommodating the suggestions of the ethical committee, and answering our specific research question, we arrived at the questions that were eventually used.

\section{Process}

Separate sessions were conducted for professional and public groups. All participants were invited to attend the research and education session regarding alcohol use in pregnancy, which was presented by one of the authors (RM). The pouring task was completed after a focus group meeting (part of the wider study and not reported here) and before the education session. Questionnaires were completed by all attending the education session, prior to its commencement.

Table 1

Estimate of the number of units of alcohol contained in various serving sizes and types of alcohol

\begin{tabular}{|c|c|c|c|c|c|c|c|}
\hline $\begin{array}{l}\text { Drink volume and } \\
\text { type (\% alcohol) } \\
\text { ( } N=\text { respondents) }\end{array}$ & $\begin{array}{l}\text { 125ml white } \\
\text { wine }(9 \%) \\
(N=1024)\end{array}$ & $\begin{array}{c}250 \mathrm{ml} \mathrm{red} \\
\text { wine }(13 \%) \\
(N=1018)\end{array}$ & $\begin{array}{l}\text { 125ml white } \\
\text { wine }(13 \%) \\
(N=1000)\end{array}$ & $\begin{array}{c}\text { Half pint } \\
\text { beer }(3.5 \%) \\
(N=1012)\end{array}$ & $\begin{array}{l}\text { Pint strong } \\
\text { lager }(5 \%) \\
(N=1011)\end{array}$ & $\begin{array}{c}\text { Bottle of } \\
\text { alcopop } \\
(5 \%) \\
(N=982)\end{array}$ & $\begin{array}{c}\text { 50ml vodka } \\
(37.5 \%) \\
(N=989)\end{array}$ \\
\hline $\begin{array}{l}\text { Correct value } \\
\text { (units) }\end{array}$ & 1.13 & 3.25 & 1.63 & 0.99 & 2.84 & 1.65 & 1.88 \\
\hline $\begin{array}{l}\text { Mean estimate of } \\
\text { units } \\
\text { [percentage of actual } \\
\text { result] }\end{array}$ & $\begin{array}{c}1.20 \\
{[106.56]}\end{array}$ & $\begin{array}{c}2.67 \\
{[82.09]}\end{array}$ & $\begin{array}{c}1.69 \\
{[103.48]}\end{array}$ & $\begin{array}{c}1.13 \\
{[114.34]}\end{array}$ & $\begin{array}{c}2.29 \\
{[80.75]}\end{array}$ & $\begin{array}{c}1.86 \\
{[112.57]}\end{array}$ & $\begin{array}{c}2.88 \\
{[153.42]}\end{array}$ \\
\hline $\begin{array}{l}95 \% \text { CI } \\
\text { [percentage of actual } \\
\text { result] }\end{array}$ & $\begin{array}{c}1.17-1.23 \\
{[103.94-} \\
109.18]\end{array}$ & $\begin{array}{c}2.62-2.72 \\
{[80.54-} \\
83.65]\end{array}$ & $\begin{array}{c}1.65-1.72 \\
{[101.5-} \\
105.45]\end{array}$ & $\begin{array}{c}1.1-1.16 \\
{[111.14-} \\
117.53]\end{array}$ & $\begin{array}{c}2.25-2.34 \\
{[79.08-} \\
82.43]\end{array}$ & $\begin{array}{c}1.81-1.91 \\
{[109.40-} \\
115.65]\end{array}$ & $\begin{array}{c}2.81-2.96 \\
{[149.40-} \\
157.44]\end{array}$ \\
\hline $\begin{array}{l}\text { Range } \\
\text { [percentage of actual } \\
\text { result] }\end{array}$ & $\begin{array}{c}0.3-6 \\
{[26.55-} \\
530.97]\end{array}$ & $\begin{array}{c}1-6 \\
{[30.77-} \\
184.62]\end{array}$ & $\begin{array}{l}0.5-3.5 \\
{[30.67-} \\
214.72]\end{array}$ & $\begin{array}{c}0.5-6 \\
{[50.51-} \\
606.06]\end{array}$ & $\begin{array}{c}0.5-6 \\
{[17.61-} \\
211.27]\end{array}$ & $\begin{array}{c}0-5 \\
{[0.0-} \\
303.03]\end{array}$ & $\begin{array}{l}0.5-10 \\
{[26.6-} \\
531.91]\end{array}$ \\
\hline
\end{tabular}

Individuals were asked to fill in each question to the best of their ability. Pouring tasks were conducted using a standard protocol, described in Box 1. All glasses were visible on a table, and each participant followed the same process of pouring a beverage into the small glass, then the large glass, and finally the tumbler. Each glass was emptied prior to the next being filled.
Questionnaires were also collected at professional and public conferences across the U.K. where RM was an invited speaker. Finally, for those responding to advertisements but unable to attend sessions, an online questionnaire was available.

\section{Box 1}

\section{Questions asked during pouring tasks set and glasses used, with the type of content to be poured into each glass}

- Participants were asked the two following broad questions. The first question was posed and all three glasses poured before asking the second question. Each Glass was emptied before the next pour was attempted.

- You return at the end of a long day at work and pour out a drink, please pour what you would normally pour into each glass.

- Now please try and pour as accurately as possible one unit of each.

- Three different glasses and two types of alcohol (All purchased from High Street supermarket and coloured water used instead of wine/spirit)

- $150 \mathrm{ml}$ glass $13 \%$ wine

- $\quad 350 \mathrm{ml}$ glass $13 \%$ wine

- 200ml whisky tumbler $40 \%$ malt whisky 


\section{Statistical analysis}

For each value on the knowledge questionnaire, frequency data including means, median, standard deviations, 95\% confidence intervals, range for unit estimations and percentage of a unit were calculated. Extreme outliers were excluded, and values of skewness and kurtosis were used to analyse normal distribution of frequency data. Where distributions were not normal, comparisons between the professional and the general public, as well as between genders, were conducted using non-parametric tests. These included the Mann-Whitney $U$ test, as recommended by Field (2009). For the pouring task, frequency data were collected and the mean percentage deviation of accuracy was calculated. Normality was tested using the Kolmogorov-Smirnov test. The Mann-Whitney $U$ test was used to test for significance. The values were compared by gender, age and profession (Field, 2009). Only two groups were compared at any one time; therefore, post hoc corrections were not made. All data were entered and analysed using SPSS version 18.

Table 2

Demographic data from questionnaires and pouring task

\begin{tabular}{|c|c|c|c|c|}
\hline & \multicolumn{2}{|c|}{ Questionnaire } & \multicolumn{2}{|c|}{ Pouring Data } \\
\hline & Number & Percentage & Number & Percentage \\
\hline Public & 688 & 57.1 & 112 & 80.0 \\
\hline Professional & 577 & 42.9 & 28 & 20.0 \\
\hline Total & 1265 & 100.0 & 140 & 100.0 \\
\hline Male & 174 & 16.2 & 30 & 21.4 \\
\hline Female & 897 & 83.8 & 110 & 78.6 \\
\hline Mean age & \multicolumn{2}{|c|}{43.29} & \multicolumn{2}{|c|}{43.98} \\
\hline Age Range & \multicolumn{2}{|c|}{$18-75$} & \multicolumn{2}{|c|}{$18-75$} \\
\hline $18-29$ & 162 & 16.3 & 21 & 15.2 \\
\hline $30-39$ & 195 & 19.6 & 21 & 15.2 \\
\hline $40-49$ & 309 & 31.1 & 51 & 37.0 \\
\hline $50-59$ & 265 & 26.7 & 35 & 25.4 \\
\hline $60+$ & 62 & 6.2 & 10 & 7.2 \\
\hline
\end{tabular}

\section{Questionnaire findings}

When informed of both the volume of liquid and its alcohol content, the majority of participants made estimations of the unit content within $20 \%$ of the actual figure. This did not hold true for whisky, where the estimates were, on average, $50 \%$ above the expected figure. Further, the range of values observed was wide for all glass sizes and percentage volumes of alcohol. The upper end of this range varied, with overestimates from $184 \%$ to $606 \%$ of actual figures. There did not appear to be any clear pattern evident from the data. When comparing groups, professionals were more accurate in calculating the actual units of vodka (Mann Whitney $U=104415.5, p=<0.001$ ) and strong lager (Mann Whitney $U=114752.5, p=0.02$ ). Men were more accurate than women at calculating the

\section{RESULTS}

\section{Sample}

One hundred forty people completed the pouring task and 1,265 questionnaires were completed. Table 2 presents the demographic breakdown of the study. Fifty-seven percent ( $n=688)$ were non-professionals and $83 \%(n=897)$ were female. All adult age groups were represented in the sample, with a mean age of 43 (range 18-75) for the questionnaire and 44 for the pouring task. Table 1 presents the number of participants that completed each question, as well as the findings. Many participants left the alcohol calculation section blank. Despite extreme outliers being excluded (four in total), the data remained non-normally distributed. Table 3 presents the findings from this task. Six people, for personal reasons, declined to pour a glass of whisky. The results from the wider study on knowledge of FASD have been submitted for publication elsewhere; an overall finding was that $86.7 \%$ of the general public and $93.8 \%$ of professionals had heard about FASD, but only $26.9 \%$ and $33.5 \%$ of those groups, respectively, could confidently predict what level of alcohol exposure in pregnancy would be considered a clear risk. number of units in $125 \mathrm{mls}$ of wine at 13\% alcohol concentration (Mann Whitney $U=52415, p=0.05$ ) and in half a pint of beer at 3.5\% alcohol concentration (Mann Whitney $U=52415, p=0.05$ ). There were no other statistically significant differences seen when comparing the different levels of alcohol knowledge by profession, age or gender.

\section{Pouring task}

The pouring task (Table 3 and Figure 1) showed a range of findings; the amounts poured varied greatly. Glass size had a significant effect on the outcome of individual "normal" pouring behavior (Wilcoxon Matched pair test $z=-9.21, p$ $=<0.001$ ). The size of the larger glass made some people more cautious when trying to pour a unit, but had the 
Table 3

Pouring task: Volume poured in millilitres

\begin{tabular}{|c|c|c|c|c|c|c|}
\hline \multicolumn{3}{|c|}{ Task requested } & $N$ & Median & \multicolumn{2}{|c|}{ Range } \\
\hline \multicolumn{3}{|c|}{$\begin{array}{l}\text { Pour a normal drink wine } 13 \% \text { : Small glass } \\
\text { [percentage compared to a unit] }\end{array}$} & 140 & $110[144.26]$ & \multicolumn{2}{|c|}{$30-150[39.34-196.72] \mathrm{IQR}=39.34$} \\
\hline \multicolumn{3}{|c|}{$\begin{array}{l}\text { Pour a normal drink wine } 13 \%:: \text { Large glass } \\
\text { [percentage compared to a unit] }\end{array}$} & 140 & 90 [118.03] & \multicolumn{2}{|c|}{$50-355[65.57-465.57] \mathrm{IQR}=44.26$} \\
\hline \multicolumn{3}{|c|}{ Comparison with Wilcoxon matched pair analysis } & \multicolumn{4}{|c|}{$Z=-9.21, p=<0.001$} \\
\hline \multicolumn{3}{|c|}{$\begin{array}{l}\text { Pour one unit: Small glass wine 13\%: [percentage } \\
\text { compared to a unit] }\end{array}$} & 140 & 155 [203.28] & \multicolumn{2}{|c|}{$30-150[39.34-196.72] \mathrm{IQR}=98.36$} \\
\hline \multicolumn{3}{|c|}{$\begin{array}{l}\text { Pour one unit: Large glass wine 13\%: [percentage } \\
\text { compared to a unit] }\end{array}$} & 140 & $92.5[121.31]$ & \multicolumn{2}{|c|}{$25-190[32.79-249.18] \mathrm{IQR}=52.46$} \\
\hline \multicolumn{3}{|c|}{ Comparison with Wilcoxon matched pair analysis } & \multicolumn{4}{|c|}{$Z=-2.56, p=0.01$} \\
\hline \multicolumn{3}{|c|}{$\begin{array}{l}\text { Pour a normal measure of Whisky [percentage } \\
\text { compared to a unit] }\end{array}$} & 134 & $50[200]$ & \multicolumn{2}{|c|}{$10-90[40-360] \mathrm{IQR}=60$} \\
\hline \multicolumn{3}{|c|}{$\begin{array}{l}\text { Pour one unit of Whisky [percentage compared to a } \\
\text { unit] }\end{array}$} & 140 & $37.5[150]$ & \multicolumn{2}{|c|}{$10-60[40-240] \mathrm{IQR}=100$} \\
\hline \multicolumn{3}{|c|}{ Comparison with Wilcoxon matched pair analysis } & \multicolumn{4}{|c|}{$Z=-6.94, p=<0.001$} \\
\hline \multicolumn{7}{|c|}{$\begin{array}{l}\text { Note. Actual expected value for one unit: Wine } 13 \%=76 \mathrm{ml} \text {; Whisky } 40 \%=25 \mathrm{ml} \text {. As results non parametric Median and ra } \\
\text { only. (Inter Quartile Range for percentage = IQR) }\end{array}$} \\
\hline \multicolumn{7}{|l|}{ Table 4} \\
\hline \multicolumn{7}{|c|}{$\begin{array}{l}\text { Results showing the difference between gender and population of study regarding accuracy of pouring (combined } \\
\text { total difference for all types of drink) }\end{array}$} \\
\hline & \multirow[b]{2}{*}{$N$} & \multirow[b]{2}{*}{ Median } & & Range & \multirow{2}{*}{$\begin{array}{l}\text { Man Whitney } \\
\text { U score }\end{array}$} & \multirow[b]{2}{*}{$p$ Value } \\
\hline & & & Min & Max & & \\
\hline Male & 30 & 167.65 & 69.07 & 218.58 & \multirow{2}{*}{1480.50} & \multirow{2}{*}{0.389} \\
\hline Female & 110 & 156.67 & 79.18 & 244.26 & & \\
\hline Public & 112 & 157.24 & 69.07 & 244.26 & \multirow{2}{*}{1473.56} & \multirow{2}{*}{0.623} \\
\hline Professional & 28 & 159.89 & 79.18 & 211.26 & & \\
\hline
\end{tabular}

opposite effect on others. There were also significant differences between the amounts people poured when asked to demonstrate their routine pouring behavior and when asked to try and pour measures of alcohol accurate to a unit (Wilcoxon Matched pair tests $z=-6.49, p \leq 0.001$ ). Some, when asked to pour what they would normally pour, poured up to $456 \%$ more than a single unit. The skewed nature of the data, with the wide range of volumes, suggested that a few people were particularly poor at estimation. Table 4 shows the comparison by gender and population studied for the combined percentage deviation. No significant findings were seen.

\section{DISCUSSION}

Consistent with our hypothesis, the results highlight the inability of both members of the general public and health professionals to estimate the alcohol concentration in their drinks and, in some cases, to pour accurately. Unlike other studies, ours found no real gender difference, possibly because of the numbers in each group. Although participants showed much cautiousness about the amount poured, there was a small group who were very bad at pouring accurately, especially when demonstrating their normal pouring behavior with spirits, where much wider ranges were seen with the larger glass. This skewed the findings. Further, this did not seem to be influenced by participants' broader knowledge of alcohol units. Glass size was also found to have an effect on accuracy in wine pouring, implying that, for a small but significant group at least, smaller glass sizes would decrease health risks.

\section{Impact on public health}

The harm from alcohol was highlighted as a growing concern in a series of reports published by the World Health Organization (World Health Organization, 2004, 2010, 2011). The annual cost of this harm in the U.K. was estimated to be $£ 2,704$ million in a cabinet office report from 2008 (Hiat, 2008). 
Figure 1

Histogram showing the number of people pouring different volumes compared to a UK unit. One unit is $100 \%$

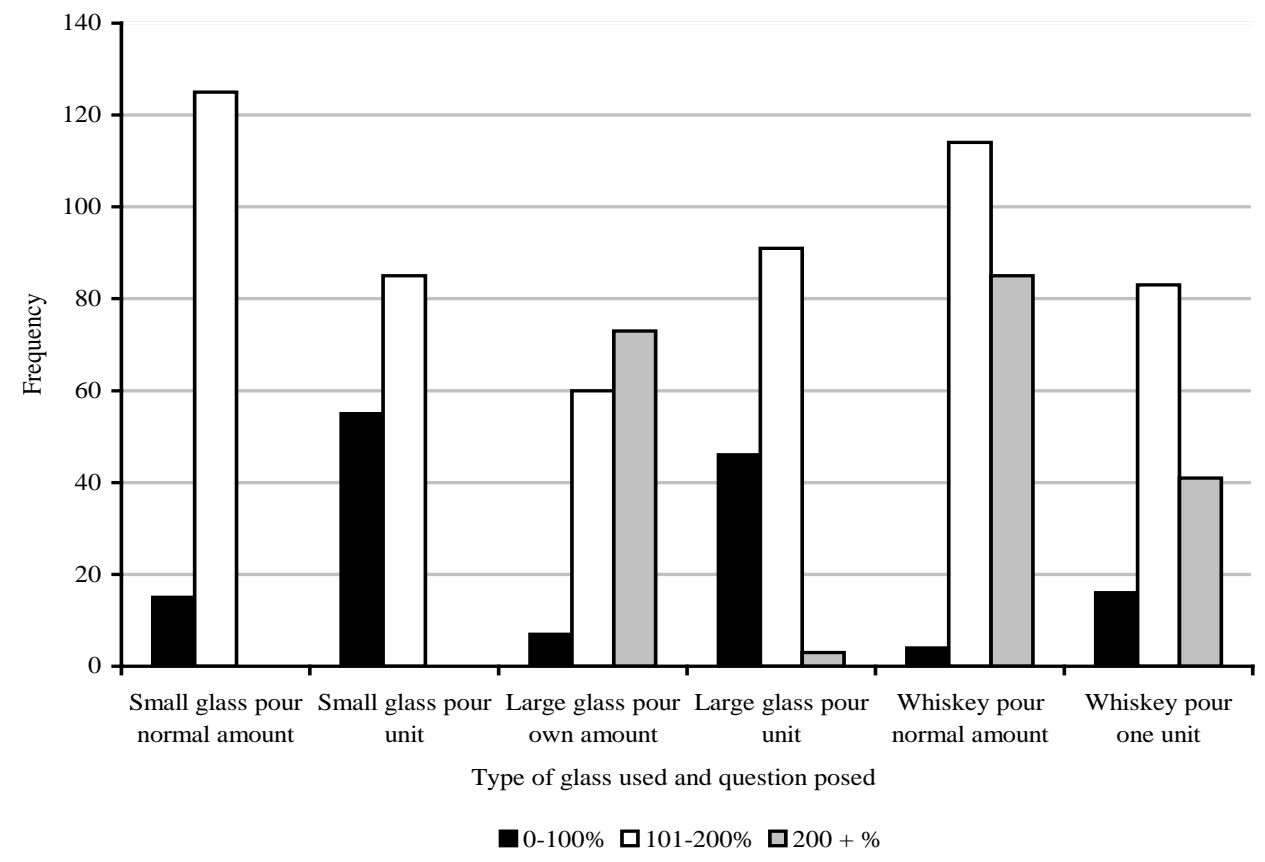

The increasing size of glasses and the high concentration of alcohol by volume suggest a potentially worrying trend, especially for those least able to accurately estimate consumption. Our findings raise the question of what undermines people's ability to estimate quantities of alcohol: preconceived ideas, a true lack of understanding, or another reason as yet unidentified? The finding that glass size affected the amounts being poured and the ability of drinkers to accurately predict and pour quantities of alcohol has potential implications for the sizes of glass that are used and sold for different types of drink.

Whilst our results are far too provisional to be conclusive, they do suggest the need for further exploration of the impact of both the size of glasses and the increasing strength of alcohol, in order to guide future policy development in this area.

\section{Impact of knowledge on drinking advice in pregnancy}

Whilst these results may be considered provisional, they strengthen our argument from 2005 that due to inaccuracies in their estimates of the quantity of alcohol they consume, and due to uncertain additional environmental risks, women should be advised not to consume alcohol in pregnancy (Mukherjee et al., 2005). Different countries continue to offer different guidance for drinking in pregnancy; for example, the U.S. suggests that no alcohol is safe, whilst the U.K. guidance is that although it is better to avoid alcohol, drinking 1-2 units once or twice a week is unlikely to cause harm (International Centre for Alcohol Policies, 2009). Our results reveal the problem with telling women that they can drink 1-2 units: their knowledge of what a unit is and, for some, their accuracy in identifying one is poor. This advice may well put individuals in a high-risk category without their realising it.

A statement that a behavior is safe should only be made when there is certainty that it is safe for all, especially when risks may lead to a condition with lifelong consequences, such as FASD. Studies have produced mixed findings regarding effects of alcohol consumption on neonatal development, especially at low levels of exposure. Whilst some studies, including some large population-based epidemiological studies, have shown low-level consumption to have limited effect (Alati et al., 2008; Disney et al., 2008; Henderson, Gray et al., 2007; Henderson, Kesmodel, \& Gray, 2007; Kelly et al., 2010; O'Leary et al., 2010), others-including similar populationbased studies, but also animal research-have shown that there may be the possibility of harm. This is especially, but not exclusively, related to neurodevelopment and later mental health outcomes (Chaudhuri, 2004; Ieraci \& Herrera, 2007; Jacobson \& Jacobson, 1999; Sayal et al., 2007; Sayal et al., 2009). These same studies confirmed the dose-response relationship with alcohol. High levels of exposure led to the most harm and the greatest expression of the physical characteristics of the disorder.

Methodological criticisms of the studies on both sides of the argument have also been made. For example, it has been argued that the measures used in the epidemiological research were insensitive to change (Sayal, 2009). Others have argued about difficulties in extrapolating animal data to humans (Abel, 2009). This shows that the picture remains unclear. 
Our original paper suggested that due to uncertainty about levels of risk, it would be better for pregnant women to avoid alcohol. Our findings from this study would suggest this remains true. Although individual risk cannot be measured, despite all the recent evidence, what is clear is that high exposure relates to high risk and low exposure to low risk. The only truly safe message regarding consumption is that no exposure to alcohol means no risk.

\section{Limitations}

This study had some limitations. A self-selected group may not reflect the true level of knowledge of the general public or of most health professionals, due to potential selection bias. There was a gender bias, in that far more women participated. The study does, however, suggest a trend that warrants further investigation: the size and shape of the glasses used may have influenced participants' pouring behavior. The exact nature of this influence seemed to vary, with the larger glass inducing sometimes recklessness and sometimes caution, but as the same set of glasses was used in all cases, the data is consistent for everyone tested, allowing comparisons to be made. With regards to the questionnaire, it is not known why some people did not complete all the questions. It may be a reflection of a lack of knowledge of how to calculate units, or simply a wish not to participate.

\section{Conclusions}

Our results suggest that while providing consumers with information about alcohol units is important, it does not appear to prevent behavior that may lead people to consume more alcohol than they realize. Making smaller glasses available for those least able to pour accurately, and making it easier for people to judge and estimate alcohol content, may reduce this risk. In pregnancy, the importance of this is magnified by continuing uncertainty about the actual level of potential risk that alcohol consumption poses to the fetus. Given the increasing prevalence of FASD in many societies, and our predominantly female participants' inaccurate assessments of the alcohol content of the drinks they poured, only complete abstention from alcohol can guarantee that there is no risk to the fetus.

\section{Acknowledgements}

Many thanks to E. Riley for comments made on early drafts of the paper and P. Cook for comments regarding statistical presentation of the paper.

\section{Reference}

Abel, E. L. (2009). Fetal Alcohol Syndrome: Same old same old. Alcohol, 104, 1274-1275. doi: 10.1111/j.1360-0443.2008.02481.x

Alati, R., MacLeod, J., Hickman, M., Sayal, K., May, M., Davey Smith, G., \& Lawlor, D. A. (2008). Intrauterine exposure to alcohol and tobacco use and childhood IQ: Findings from a prenatal offspring comparison with Avon Longitudinal Study of Adults and Children. Paediatric Research, 64, 659-666. doi: 10.1203/PDR.0b013e318187cc31

Chaudhuri, J. D. (2004). Effect of a single dose of ethanol on developing skeletal muscle on chick embryo. Alcohol, 34, 279-283. doi: 10.1016/j.alcohol.2004. 07.012

Department of Health. (1995). Sensible drinking report of an interdepartmental working group. Wetherby, United Kingdom: Author.

Disney, E. R., Iacono, W., McGue, M., Tully, E., \& Legrand, L. (2008). Strengthening the case: Prenatal alcohol exposure is associated with increased risk of conduct disorder. Paediatrics, 122, e1225-e1230. doi: $10.1542 /$ peds.2008-1380

Field, A. (2009). Discovering statistics using SPSS. (Third ed.). London, United Kingdom: Sage Publishing.

Gill, J. S., \& Donaghy, M. (2004). Variations in the alcohol content of a drink of wine and spirit poured by a sample of the Scottish population. Health Education Research, 19, 485-491. doi: 10.1093/her/cyg059

Gill, J. S., Donaghy, M., Guise, J., \& Warner, P. (2007). Descriptors and accounts of alcohol consumptions: Methodological issues piloted with female undergraduate drinkers in Scotland. Health Education Research, 22, 27-36. doi: 10.1093/her/ cyl037

Gill, J. S., \& O'May, F. (2007). Practical demonstration of personal daily consumption limits: A useful intervention tool to promote responsible drinking among UK adults. Alcohol and Alcoholism, 42, 436441. doi: 10.1093/alcalc/agm049

Gray, R., Mukherjee, R. A. S., \& Rutter, M. (2007). Alcohol consumption during pregnancy and its effect on neurodevelopment. Addiction, 104, 1270-1273. doi: 10.1111/j.1360-0443.2008.02441.x

Henderson, J., Gray, R., \& Brocklehurst, P. (2007). Systematic review of the effects of low to moderate prenatal alcohol exposure on pregnancy outcome. Journal Royal College of Obstetricians and Gynaecologists, 114, 243-252. doi: 10.1111/j.14710528.2006.01163.x.

Henderson, J., Kesmodel, U., \& Gray, R. (2007). Systematic review of fetal effects of prenatal binge drinking. Journal of Epidemiology and Community Health, 61, 1069-1073. doi:10.1136/jech.2006. 054213

Hiat, D. H. (2008). The cost of alcohol harm to the NHS. England, London, United Kingdom: The Cabinet Office.

Ieraci, A., \& Herrera, D. G. (2007). Single alcohol exposure in early life damages hippocampal stem cell progenitor cells and reduces adult neurogenesis. Nuerobiology of Disease, 26, 597-605. doi: 10.1016/j.nbd.2007.02.011

International Centre for Alcohol Policies. (2009). International Guidelines on Drinking in Pregnancy. http://www.icap.org/Table/InternationalGuidelinesO nDrinkingAndPregnancy

Jacobson, J. J., \& Jacobson, S. W. (1999). Drinking moderately in pregnancy: Effects on child 
development. Alcohol Research and Health, 23, 2530.

Kelly, Y., Sacker, A., Gray, R., Kelly, J., Wolke, D., \& Quigley, M. A. (2007). Light drinking in pregnancy, a risk for behavioral problems and cognitive deficits at 3 years of age. International Journal of Epidemiology, 38, 129-140. doi: 10.1093/ije/dyn230

Kelly, Y. J., Sacker, A., Gray, R., Kelly, J., Wolke, D., Head, J., \& Quigley, M. A. (2010). Light drinking in pregnancy: Still no increased risk for socio emotional difficulties or cognitive deficits at 5 years of age. Journal of Epidemiology and Community Health, 8, 1-8. doi: 10.1136/jech.2009.103002

Kerr , W., Patterson, D., Koenen, M. A., \& Greenfield, T. K. (2009). Large drinks are no mistake: Glass size and not shape affect alcoholic beverage drink pours. Drug and Alcohol Review, 28, 360-365. doi: 10.1111/j.1465-3362.2009.00056.x

Lader, D., \& Goddard, E. (2006). Drinking: Adults' behavior and knowledge in 2006. London, United Kingdom: Office of National Statistics.

Lemmens, P. H. (2006). The alcohol content of self report and standard drinks. Addiction, 89, 593-601. doi: 10.1111/j.1360-0443.1994.tb03336.x

Mukherjee, R. A. S., Hollins, S., Abou-Saleh, M., \& Turk, J. (2005). Low level alcohol consumption and the fetus. BMJ, 330, 375-376. doi: 0.1136/bmj.330.7488. 375

Mukherjee, R. A. S., Hollins, S., \& Turk, J. (2006). Psychiatric comorbidity in Fetal Alcohol Syndrome. The Psychiatrist 30: 194-195. doi: 10.1192/pb.30. 5.194-c

O'Leary, C., Nasser, N., Kurinczuk, J. J., deKlerk, N., Geelhoed, E., Elliott, E., \& Bower, C. (2010). Prenatal alcohol exposure and risk of birth defects. Paediatrics, 126, e843-e850. doi: 10.1542/peds. 2010-0256

Office of National Statistics. (2008). Smoking and drinking amoung adults. London, United Kingdom: Author.

Office of National Statistics. (2009). Drinking adult behavior and knowledge. London, United Kingdom: Author.
Onofrio, B. M., Van Hulle, C. A., Waldman, I. D., Rodgers, J. L., Rathouz, P. J., \& Lahey, B. B. (2007). Causal inferences regarding prental alcohol exposure and childhood externalising problems. Archives of General Psychiatry, 64, 1296-1304. doi: 10.1001/ archpsyc.64.11.1296

Patra, J., Bakker, R., Irving, H., Jaddoe, V. W. V., Malini, S., \& Rehm, J. (2011). Dose response relationship between alcohol consumption before and during pregnancy and risk of low birthweight preterm birth and small for gestational age systematic review and metaanalysis. Bristish Journal of Ostetrics and Gynaecology, 118 (2), 1411-1421. doi: 10.1111/j. 1471-0528.2011.03050.x BJOG

Sayal, K. (2009). Commentary: Light drinking in pregnancy: can a glass or two hurt. International Journal of Epidemiology, 38, 140-142. doi: 10.1093/ ije/dyn370

Sayal, K., Heron, J., Golding, J., Alati, A., Davey Smith, G., Gray, R., \& Emond, A. (2009). Binge patterns of alcohol consumption during pregnancy and childhood mental health outcomes. Paediatrics, 123, e289-e296. doi: 10.1542/peds.2008-1861

Sayal, K., Heron, J., Golding, J., \& Emond, A. (2007). Prenatal alcohol exposure and gender differences in childhood mental health problems: A longitudinal population based study. Paediatrics, 119, 426-434. doi: 10.1542/peds.2006-1840

The Cabinet Office. (2004) Alcohol reduction strategy. London, United Kingdom: Author.

Wasinski, B., \& Illersum, K. (2005). Shape of glass and alcohol poured, comparitive study of effect of practice and concentration. BMJ, 331, 1512-1514. doi:10.1136/bmj.331.7531.1512

World Health Organization. (2004). Global status report on alcohol 2004. Singapore, Asia: Author

World Health Organization. (2010). Global strategy to reduce the harmful effect of alcohol. Geneva, Switzerland: Author.

World Health Organization. (2011). Global status report on alcohol and health. Geneva, Switzerland: Author. 